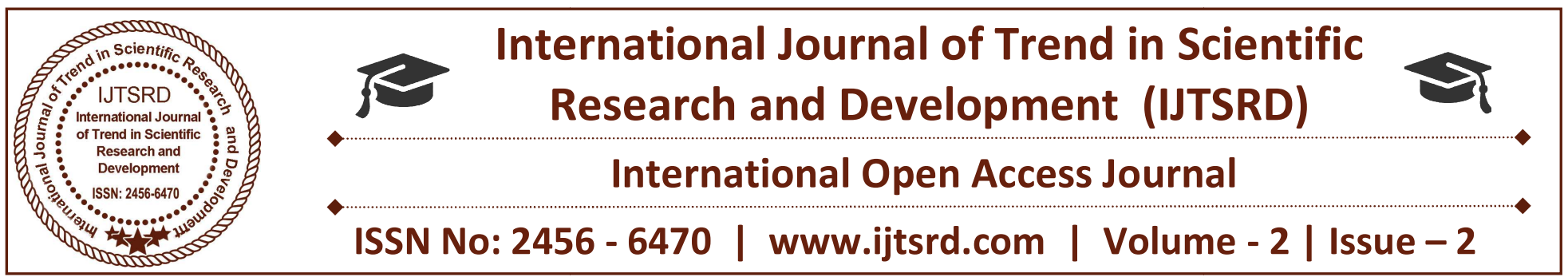

\title{
Application \& Analysis of Banana Stem Fibre use as Construction Material
}

Chaudhari Tejas Prakash

PG Student, Civil Engineering Department, SORT, People's University, Bhopal, Madhya Pradesh, India
Govind Singh Solanki

A.P, Civil Engineering Department, SORT, People's

University, Bhopal, Madhya Pradesh, India

\section{Hirendra Pratap Singh}

A.P, Civil Engineering Department, SORT, People's

University, Bhopal, Madhya Pradesh, India

\section{ABSTRACT}

This project reviews the properties of banana fibres. These banana fibres were investigated by different researchers as a construction material to be used in composites (such as mortar and concrete). The different research carried out and the conclusions drawn are briefly presented. The aim of review is to compile the available data of banana fibres evaluated in last few decades and thus, it can be used as a references/guideline for the upcoming result of a particular fibre. Natural fibres are use to increase the strength properties of the composites. But all properties cannot be improved at the same time because fibres have their own characteristics. So it is recommended that appropriate fibre should be use for a particular purpose. Also, there should be guideline/criteria for acceptance of banana fibres, because of variable properties of a particular fibre in different regions. No doubt, banana fibres can be used in a variety of manners, but still, there is a need of research for investigating the further properties of fibres.

\section{INTRODUCTION}

Fibres are thread like materials which can be used for different purposes. Fibres produced by plants (vegetable, leaves and wood), animals and geological processes are known as natural fibres. Researchers have used plant fibres as an alternative source of steel and/or artificial fibres to be used in composites (such as cement paste, mortar and/or concrete) for increasing its strength properties.

Natural fibres are cheap and locally available in many countries. So their use as a construction material for increasing properties of composites costs a very little (almost nothing when compared to the total cost of the composites). Their use can lead to have sustainable development. Another benefit may also include the easy usage/handling of fibres due to their flexibility, because the problem arises when high percentage of fibres is to be used as in case of steel fibres. But for use of very high percentage of fibres, there is a need to invent a methodology for casting. Volume fraction and fibres content are two terminologies used for expressing the quantities of fibres in a given composites. Volume fraction can be the part of total volume of composite or the part of volume of any ingredient to be replaced. Fibers content can be the part of total weight of composite or the part of weight of any ingredient to be replaced. Researchers have emphasized on the selection of optimum quantity of fibres along with the optimum fibres length (for example, matrix/composite with 3\% volume fraction of fibres and $4 \mathrm{~cm}$ fibres length can achieved maximum strength, any further increase/decrease in volume fraction and/or fibres length may decrease strength of matrix/composite). 
Fibres reinforced composites can be used for many civil engineering applications including roofing tiles, corrugated slabs, simple slab panels, boards and mortar etc.

The Banana fibre is Second largest produced fruit after citrus, contributing about $16 \%$ of the world's total fruit production. India is Largest producer of banana, contributing to $27 \%$ of world's banana production. Banana fibre has a high tensile strength, resistant to rotting and its specific flexural strength is near to that of glass fibre. The production of banana fibre is highest in Maharashtra (3924.1 thousand tonnes) than other state of India.

Banana plant not only gives the delicious fruit but it also provides textile called the Banana fibre. It grows easily as it sets out young shoots and is most commonly found in hot tropical climates. These fibre are obtain after the fruit is harvested $\&$ fall in the group of bastfibers. Banana fiber is extracted from banana trees bark, the trunk is peeled. The browngreen skin is thrown away retaining the cleaner or white portion which will be processed in to knotted fibers. The fiber are extracted through Hand extraction machine composed of either serrated or non serrated knives. The extracted fibers are sun-dried which whitens the fiber. Once dried, the fiber are ready to knotting. A bunch of fibers are mounted or clamped on a stick to facilitate segregation. These each fiber is separated according to fiber sizes \& grouped accordingly.

Banana fibres are an abundant, low-cost, and generally underutilized resource. Often, they are produced as waste by-products of industrial or agricultural processes. In many countries, for example, flax is grown primarily for its oilseed, and the straw is discarded or burned as a waste material. However, the fibres within the straw is one of the most durable and strong natural fibres, making it an ideal candidate for an effective fibres reinforcement in concrete, similarly banana is grown for the fruit however the disposal of the stem is a major issue.

Banana fibres, a ligno-cellulosic fibres, obtained from the pseudo-stem of banana plant (Musa sepientum), is the best fibres with relatively good mechanical properties. The "pseudo-stem" is a clustered, cylindrical aggregation of leaf stalk bases. Banana fibres at present are a waste product of banana cultivation and are either not properly utilized or partially done so. The extraction of fibres from the pseudo stem is not a common practice and much of the stem is not used for production of fibres. This is reflected from the relatively expensive price of banana fibres when compared to other natural fibres. The buyers for banana fibres are erratic and there is no systematic way to extract the fibres regularly. Hence the useful applications of such fibres would regularize the demand which would be reflected in a fall of the prices.

Natural fibres present important advantages such as low density, appropriate stiffness and mechanical properties and high disposability and renewability. Moreover, they are recyclable and biodegradable. There has been lot of research on use of natural fibres in reinforcements. Banana fibres, lingo-cellulosic fibres, obtained from the pseudo-stem of banana plant (Musa Sepientum), area best fibres with relatively good mechanical properties. The "pseudo-stem" is a clustered, cylindrical aggregation of leaf stalk bases. Banana fibres at present are a waste product of banana cultivation and either not properly utilized or partially done so. The extraction of fibres from the pseudo stem is not a common practice and much of the stem is not used for production of fibres. This is reflected from the relatively expensive price of banana fibres (Table I) when compared to other natural fibres. The buyers for banana fibres are erratic and there is no systematic way to extract the fibres regularly. Useful applications of such fibres would regularize the demand which would be reflected in a fall of the prices.

\subsection{Extraction of banana fibre}

Banana fibre is extracted, not on a commercial worthwhile scale anywhere in the country. For extraction of fibres from the pseudo stem, the most common method followed in Indian villages is hand scrapping, i.e. to scrap the stem with blunt metal edge. The drawback of hand scrapping is that the fibre output is very low. The essentially hand driven process of extracting banana fiber is now set to change with the invention of the Banana Fiber Separator Machine. An easier and quicker way of extracting fibres is to use a machine extractor, called Raspador, Banana Fiber is extracted from Banana pseudo stem sheaths. Some efforts to extract the fibre by conventional methods like Hand extraction are being made in state of Kerala but the quantity of fibre produced is quite small. In some banana growing countries of the world like Philippines, Uganda, 
China, and Indonesia systematic extraction of banana fibre is being carried out.

The plants are cut down as soon as the fruits are harvested. The trunk is peeled. Brown-green skin is thrown away retaining the cleaner or white portion which will be processed into knotted fibers. To extract the fibre, the pseudo stem is cut at the bottom at an angle, and its sheaths are removed, as each series of leaf sheaths produces different grades of fibers. It would be desirable to separate them according to the classification mentioned above prior to the cleaning or stripping that would enable the artisans to market the fibres advantageously. The fibers are extracted through hand extraction machine composed of either serrated or non serrated knives.

The peel is clamped between the wood plank and knife and hand-pulled through, removing the nonfibrous material. The extracted fibers are sun-dried which whitens the fiber. Once dried, the fibers are ready for knotting. A bunch of fibers are mounted or clamped on a stick to facilitate segregation. Each fiber is separated according to fiber sizes and grouped accordingly. To knot the fiber, each fiber is separated and knotted to the end of another fiber manually. The separation and knotting is repeated until bunches of unknotted fibers are finished to form a long continuous strand. This fiber can now be used for making various products. One more interesting fact associated with the development of this machine is that it uses the agriculture waste of banana harvests to produce silk grade fiber. These silk grade fibers are of immense help to the handicrafts and textile industry. What was previously considered an agricultural waste is now converted to a raw material for good quality silk like yarn.

Bastfibres, like banana, are complex in structure. They are generally lignocelluloses, consisting of helically wound cellulose micro fibrils in amorphous matrix of lignin and hemicelluloses. The cellulose content serves as a deciding factor for mechanical properties along with micro fibril angle. A high cellulose content and low micro fibril angle impart desirable mechanical properties for bastfibres. Lignin is composed of nine carbon units derived from substituted cinnamyl alcohol; that is, columbary, coniferyl, and syringyl alcohols. Lignin is associated with the hemicelluloses and plays an important role in the natural decay resistance of the lignocelluloses material. The composition of banana pseudo stem is as given in Table I.

\subsection{Composition of Fibres}

Table-1 - Composition of Fibres

\begin{tabular}{|l|l|l|}
\hline Sr. No & Component & $\%$ Percentage \\
\hline $\mathbf{1}$ & Cellulose & $31.27 \pm 3.61$ \\
\hline $\mathbf{2}$ & Hemicelluloses & $14.98 \pm 2.03$ \\
\hline $\mathbf{3}$ & Lignin & $15.07 \pm 0.66$ \\
\hline $\mathbf{4}$ & Extractives & $4.46 \pm 0.11$ \\
\hline $\mathbf{5}$ & Moisture & $9.74 \pm 1.42$ \\
\hline $\mathbf{6}$ & Ashes & $8,65 \pm 0.1$ \\
\hline
\end{tabular}

\subsection{Characteristics of Banana Fiber}

In most part of India, these banana trunks are thrown as agricultural waste because most of the people are ignorant about the extraction of the fibre and its utilization except Kerala where this fibre is partly used for manufacturing house hold articles. This present portion of article gives an evaluation of yield, structure and properties of banana fibres gathered from a few commercially cultivated varieties. Results indicate that variation exists in both structure and properties of fibres from different regions along the length and across the thickness of the trunk. Banana fiber is a natural fiber. It has its own physical and chemical characteristics and many other properties that make it a fine quality fiber.

Characteristics of Banana Fiber are as follows:

- Appearance of banana fiber is similar to that of bamboo fiber and ramie fiber.

- The chemical composition of banana fiber is cellulose, hemicelluloses, and lignin.

- It is a strong fiber.

- It has smaller elongation.

- It has somewhat shiny appearance depending upon the extraction.

- It is light weight.

- It has strong moisture absorption quality. It absorbs as well as releases moisture very fast.

- It is bio- degradable and has no negative effect on environment and thus can be categorized as eco-friendly fiber.

- Its average fineness is 4 to 15 tex.

\section{LITERATURE REVIEW}

Harajli \& Salloukh (1997) is said that, In addition to industrial fibers, natural organic and mineral fibers have been also investigated in reinforced concrete. Wood, Banana fibre, sisal fibre, jute fibre, bamboo 
fire, coconut fibre, asbestos and rock wool, are examples that have been used and investigated. The main aim of the research on sustainable materials is to investigate the use of natural fibers with cement/concrete mixes to improve the performance of construction components and reduce the depletion in natural resources. The demand for the agricultural fibers for concrete production would be a major incentive to Lebanese farmers to benefit from the social impact on the habitat level of living. In the preliminary program reported in this paper, cubes and standard flexural beams were tested to evaluate the structural and physical performance of concrete mixes prepared with different volumetric ratios of added fibers and different proportions of aggregates. Test results indicated that the use of natural fibers resulted in reducing the coarse aggregate quantity without affecting the flexural performance of concrete.

Majid Ali, et al (2012) was explained that the properties of different natural fibres. These natural fibres were investigated by different researchers as a construction material to be used in composites (such as cement paste, mortar and/or concrete). The different researches carried out and the conclusions drawn are briefly presented. The aim of this review is to compile the available data of different natural fibres evaluated in last few decades, and thus, it can be used as a reference/guideline for the upcoming research of a particular fibre. Natural fibres are used to increase the strength properties of the composites. But all properties cannot be improved at the same time because fibres have their own characteristics.

Krishna R. \& Sandararajan (2005) is investigated the effect of variation in chemical composition on tensile strength of four natural fibres (coir, sisal, jute and. Cannabinus fibres), when subjected to alternate wetting and drying, and continuous immersion for 60 days in three mediums (water, saturated lime and sodium hydroxide). Chemical composition of all fibres changed for tested conditions (continuous immersion was found to be critical), and fibres lost their strength. But coir fibres were reported best for retaining a good percentage of its original tensile strength for all tested conditions.

Elie Awwad, Mounir Mabsout, Bilal Hamad and HelmiKhatib, et al (2011) had explained that preliminary tests performed to produce a sustainable "green" concrete material using natural fibers such as industrial hemp, palm, and banana leaves fibers. Such material would increase the service life and reduce the life cost of the structure and would have a positive effect on social life and social economy. The demand for the agricultural fibers for concrete production would be a major incentive to Lebanese farmers to benefit from the social impact on the habitat level of living. In the preliminary program reported in this paper, cubes and standard flexural beams were tested to evaluate the structural and physical performance of concrete mixes prepared with different volumetric ratios of added fibers and different proportions of aggregates. Test results indicated that the use of natural fibers resulted in reducing the coarse aggregate quantity without affecting the flexural performance of concrete.

\section{MATERIALS AND METHODS}

\subsection{Materials and Mixing of Natural Fibres Reinforced Concrete}

\section{a. Proportions}

Mix proportions for unprocessed natural fibres reinforced concrete cannot be generalized since there are a variety of natural fibres that can be used in conjunction with the other standard ingredients such as cement, pozzolans, fine aggregates, water, and admixtures. The types of natural fibres that can be used with these standard ingredients include: bagasse, sisal, jute, coconut, banana, and palm. A brief description for each of the constituents which is used for obtaining fibres reinforced concrete is outlined below.

\section{b. Cement}

Cement that meets the specification can be used. The type of cement recommended is Type I, although Type III (high-early strength) cement can be used in order to reduce hardening retardation caused by the glucose present in most natural fibres.

\section{c. Aggregates}

The aggregates should meet the gradation requirements specified by Standard Specification for Concrete Aggregates.

\section{d. Water and Admixtures}

The water to be used for the mix should be clean and of good quality. Admixtures such as accelerating agents may be used in order to decrease the influence of the glucose retardant. If mild steel rebars are not used as additional reinforcement, calcium chloride could be used. Water-reducing admixtures and highrange water-reducing agents can be added in order to increase the workability when plastering. The use of 
organic-micro biocide is encouraged, for the prevention of bacterial attack of organic fibres.

\section{e. Fibres}

The length of fibres may vary from 25 to $500 \mathrm{~mm}$. Because fibres are natural materials, they are not uniform in diameter and length. Typical values of diameter for unprocessed natural fibres vary from 0.10 to $0.75 \mathrm{~mm}$. The mechanical properties of fibres are summarized under Technical Properties.

\section{Methods of Mixing}

The two methods of mixing and placing are (1) wet mix and (2) dry-compacted mix.

\section{(1) Wet mix :}

In the wet mix, a low volume fraction of fibres is used. The water to be added to the mix has to take into account the high natural water content in the natural fibres. The mixing procedure must comply with process and portions recommendations. Trial batches are recommended and a batching plant is required. The recommended mixing procedure is to add cement with water and additives to form slurry. Then the fine aggregates are added. Finally, fibres is added and dispersed into the slurry. The sampling is to be done according to standard practices. For compressive and flexural strength testing, standard tests are to be followed.

\section{(2) Dry-compacted mix:}

The dry-compacted mix is generally used for industrial or semi-industrial projects. In the drycompacted mix, the volume fraction of fibres used is about 10 times the volume fraction used in wet mix. The fibres are in a saturated-surface dry condition for this type of mix. Trial batches are recommended. The recommended mixing procedure is to add fibres in saturated-surface-dry condition to the cement and aggregates and then adds a very limited amount of water. Mixing can be done by hand or with mixers. For compressive and flexural strength, standards as for normal concrete are to be followed.

\subsection{Materials and Methods}

Banana fibres are obtained from KrushiTantraniketanVidhyalay, Nimbhora, DistJalgaon, State -Maharashtra Pin- 425506, and India. Banana fibres are extracted from the stems of banana plant. Longitudinal slices are prepared from stems and fed to fibres extracting machine (Figure-1). The fibres extracting machine, also known as a mechanical decorticator, consists of a pair of feed rollers and a beater. The slices were fed to the beater between the squeezing roller and the scrapper roller, (Figure-1) following which the pulp gets separated and fibres are extracted and air dried in shade.

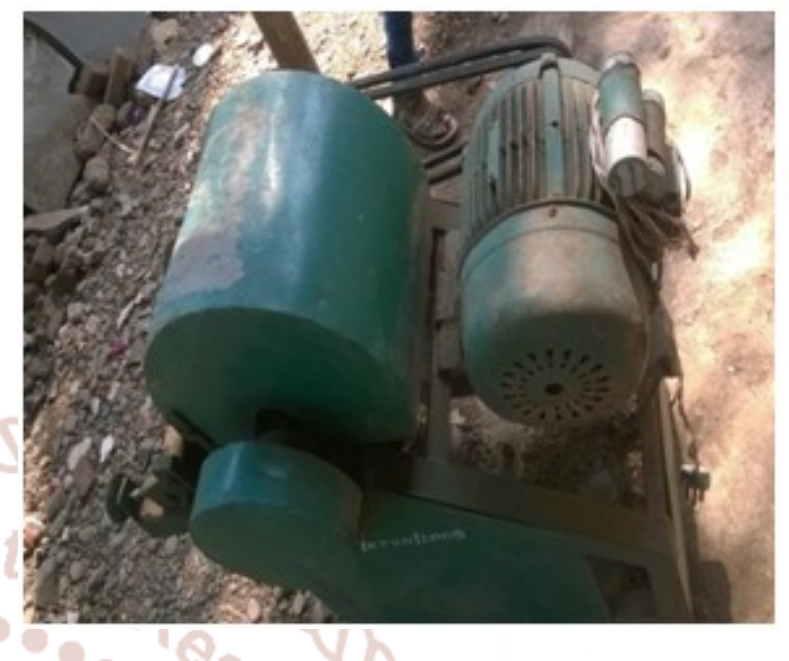

Figure-1 Fibre Extraction machine

\subsection{Testing of fibres}

\section{Conditioning}

Specimens were conditioned, at $65 \% \mathrm{RH}$ and $21^{\circ} \mathrm{C}$ for a day to ensure environmental equilibrium, prior to testing.

\section{Fibres linear density}

Fibres diameter is evaluate from optical observations under microscope as the average of five diameter measurements taken at different locations along the fibres with a range of standard deviation from 0.05 to 0.1 . Based on the diameters of the fibres, the whole fibres samples are divided into four broad categories. The diameter of the fibres is then measured at 100 different places along the length of four fibres. 100 fibres were also taken at random from the sample and their diameter is measure at 10 different places. The Tex of the fibres is calculated assuming the density of banana fibres to be $1.4 \mathrm{~g} / \mathrm{cc}$, determined using a density gradient column prepared from xylene $(0.865$ $\left.\mathrm{g} / \mathrm{cm}^{3}\right)$ and carbon tetrachloride $\left(1.595 \mathrm{~g} / \mathrm{cm}^{3}\right)$ by Kumar et.al. Figure 2, which is the cross section of fractured banana fibres, shows the circular nature of the fibres, along with the presence of some protruding fibrils. Thus for a circular cross section of the fibres, the Tex of the fibres, defined as the weight in grams of $1000 \mathrm{~m}$ of the fibres, would be related to the volume as

Tex $=$ Volume $(\mathrm{cc}) \times 1.4 \times 1000$ 


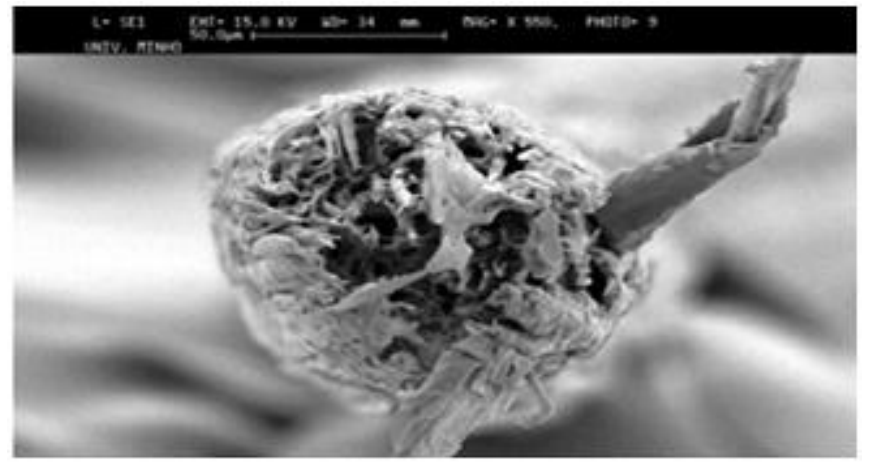

Figure-2 SEM of Banana Fibre Showing Circular C/S

\section{Single fibres tensile test}

Fibres were carefully manually separated from the bundles. Fibres ends are glued onto a paper frame according to the preparation procedure described in ASTM D3822-07 Standard. A Hounsfield tester is used to test the fibres. A load cell of 100 Newton was used for fibres testing. Due to variability of natural fibres, 20 samples are tested and the average value reported along with the variability of the data. The strain rate is varied to study its effect on properties. Pneumatic grips are used to clamp the fibres with a pressure of $0.4 \mathrm{MPa}$. When mounting specimens onto the tester, special care is taken to prevent fibres misalignment. The distance between the grips are fixed to $100 \mathrm{~mm}$ and the upper end of the fibres is clamped first and the fibres is allowed to self-align, under the weight of lower paper tab, followed by clamping of the lower end. The tenacity values are calculated based on the maximum load and the Tex of the fibres, the calculation of which has already been discussed. Modulus values are not reported as the tester had no strain gauge attachment.

\section{SEM}

A scanning electron microscope (SEM), Model Leica Cambridge S-360 was used to study the fracture surface of the tensile and impact specimens. The specimens were coated with a thin gold-palladium layer using Sputter Coater to avoid electrical charge accumulation during examination.

\section{PROCEDURE}

\subsection{Compressive Strength of the Composite Concrete}

The strength of concrete is measured primarily in terms of the compressive strength as concrete is always used for its compressive strength more than for its tensile properties. Thus we perform compressive strength analysis to analyze the effect of fibres reinforcement on the same.

\section{a.Proportion:}

The entire testing was carried out with a nominal mix of M20 as per IS 516-1959. Details about the mix used and the additions made to the same have been mentioned in the table that follows.

Table-2 Mix used and the addition made

\begin{tabular}{|c|c|c|c|c|c|c|c|c|}
\hline \multirow{2}{*}{$\begin{array}{l}\text { No. of } \\
\text { cubes }\end{array}$} & \multicolumn{4}{|c|}{ Weights in Kg } & \multirow{2}{*}{$\begin{array}{l}\text { Sikament } \\
(\mathrm{ml})\end{array}$} & \multirow[t]{2}{*}{ WC Ratio } & \multirow{2}{*}{$\begin{array}{l}\text { Fibre } \\
(\%)\end{array}$} & \multirow{2}{*}{$\begin{array}{c}\text { Fibre Wt } \\
\text { (gm) }\end{array}$} \\
\hline & Cement & Sand & Aggregate & Water & & & & \\
\hline 1 & 1.47 & 2.21 & 4.42 & 0.80 & 5.0 & 0.55 & 0 & 0 \\
\hline 1 & 1.47 & 2.21 & 4.42 & 0.80 & 5.0 & 0.55 & 1 & 81 \\
\hline 1 & 1.47 & 2.21 & 4.42 & 0.80 & 5.0 & 0.55 & 0.1 & 8.1 \\
\hline 1 & 1.47 & 2.21 & 4.42 & 0.80 & 5.0 & 0.55 & 0.2 & 16.2 \\
\hline 1 & 1.47 & 2.21 & 4.42 & 0.80 & 5.0 & 0.55 & 0.3 & 24.3 \\
\hline
\end{tabular}

\section{b. Specimen:}

Specimen used was conforming to IS 383:1970 and IS 456:2000. Size was as per the standards i.e. $150 \mathrm{mmX} 150 \mathrm{mmX} 150 \mathrm{~mm}$. The plasticizer used was $200 \mathrm{ml}$ per bag of $50 \mathrm{~kg}$ cement.

\section{c. Casting techniques:}

The procedure followed was wet mix. The proportioned ingredients were weigh batched and then mixed in the following order. Aggregates were spread

on the mixing platform. Sand was then spread over the aggregates. Fibres dressed and weighed were then the fragments were separated from the lumps and spread over the mix. 


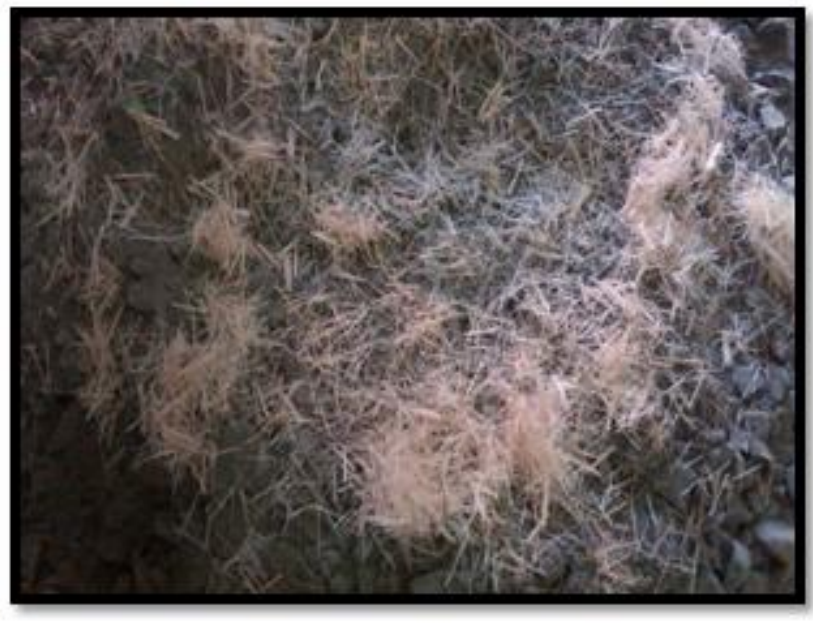

Figure-3 Wet Mixing of Fibres.

Then everything was mixed evenly and it was ensured that the fibres were mixed properly. When it is visibly understood that the fibres are mixed well cement is added slowly and then again mixed. Water is measured and added slowly with continues mixing. When all the concrete is mixed well with water the same is used to cast the cubes. In case of plasticizers the plasticizer is mixed in water and then added.

\section{d. Difficulties faced:}

1) Mixing: The number of times dry mixing is done is more increasing the effort required in case of hand mixing. Also if the cement is added first, loss of cement due to dusting increases. The dispersion of the fibres is necessary and yet difficult to attain.

Thus altogether the effort required for mixing increases increasing time required and hence reduction in efficiency if method adopted is that of hand mixing.

2) Workability: The fibres are of natural origin and majorly made up of cellulose. Cellulose being hygroscopic in nature and having a property to imbibe water it soaks up certain amount of water. This creates a deficit of water necessary to give required workability. The fibres if not dispersed properly create lumps in concrete which further reduces workability. However this problem can be avoided by ensuring that the fibres are dressed well and the dry mixing carried out if is thorough.

3) Compaction: Due to less available water and lowered workability it reflects in the compaction on concrete. Also due to the fibres present in the concrete the slurry formation is affected adversely as the water and slurry tend to get stuck with the fibres. This leads to a honeycombed structure if necessary measures are not taken. Measures taken include use of plasticizer, optimum aspect ratio of fibres, idle dry mixing, grading of aggregates.

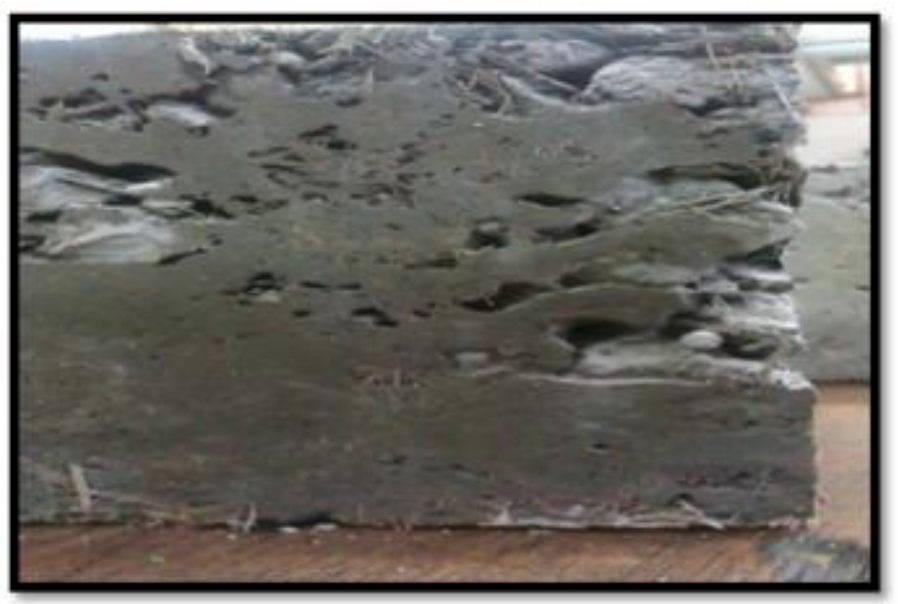

Figure-4 Improper Compaction Due to Increased Fibre Fraction.

4) Strength: with the increase in the percentage of the fibres, it is found that the strength of the concrete is decreased.

Finishing: due to presence of the fibres, it is difficult to achieve the smooth surface of the cubes this is because of the less workability due to less formation of the slurry. This can however be avoided by use of plasticizers which help in providing the perfect finish.

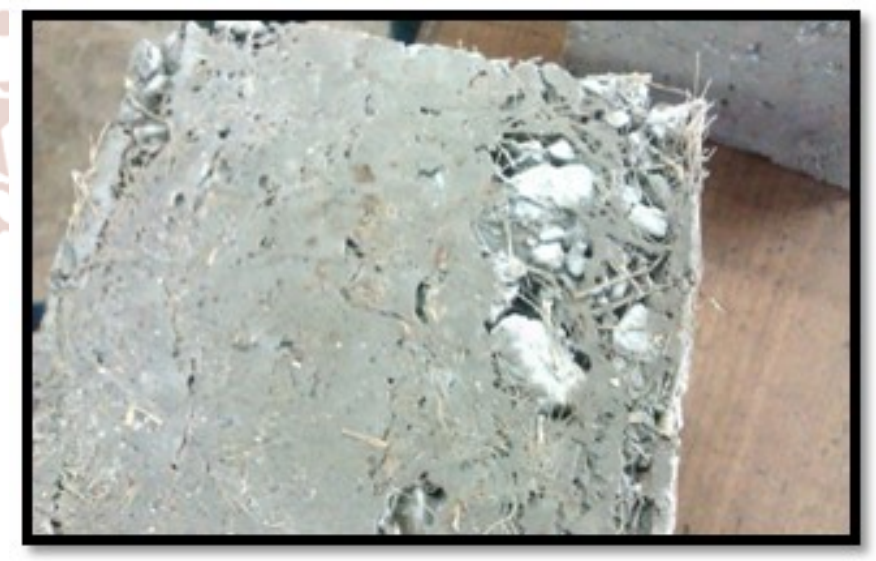

Figure-5 Improper Finishing Due to Increased Fibre Fraction.

Test for Compressive Strength of concrete specimen (IS 383:1970) 
The testing machine may be of any reliable type, of sufficient capacity for the tests and capable of applying the load at the rate specified. The permissible error shall be not greater than \pm 2 percent of the maximum load. The testing machine shall be equipped with two steel bearing platens with hardened faces. One of the platens (preferably the one that normally will bear on the upper surface of the specimen) shall be fitted with a ball seating in the form of a portion of a sphere, the centre of which coincides with the central point of the face of the platen. The other compression platen shall be plain rigid bearing block. The bearing faces of both platens shall be at least as large as, and preferably larger than the nominal size of the specimen to which the load is applied. The bearing surface of the platens, when new, shall not depart from a plane by more than 0.01 $\mathrm{mm}$ at any point, and they shall be maintained with a permissible variation limit of $0.02 \mathrm{~mm}$.

The movable portion of the spherically seated compression platen shall be held on the spherical seat, but the design shall be such that the bearing face can be rotated freely and tilted through small angles in any direction.

\section{Age at test}

Tests shall be made at recognized ages of the test specimens, the most usual being 7 and 28 days. Ages of 13 weeks and one year are recommended if tests at greater ages are required. Where it may be necessary to obtain the early strengths, tests may be made at the ages of 24 hours $\pm 1 / 2$ hour and 72 hours \pm 2 hours. The ages shall be calculated from the time of the addition of water to the dry ingredients.

\section{Procedure}

Specimens stored in water shall be tested immediately on removal from the water and while they are still in the wet condition. Surface water and grit shall be wiped off the specimens and any projecting fins removed. Specimens when received dry shall be kept in water for 24 hours before they are taken for testing.
The dimensions of the specimens to the nearest 0.2 $\mathrm{mm}$ and their weight shall be noted before testing.

\section{Placing the specimen in the Testing Machine}

The bearing surfaces of the testing machine shall be wiped clean and any loose sand or other material removed from the surfaces of the specimen which are to be in contact with the compression platens. In the case of cubes, the specimen shall be placed in the machine in such a manner that the load shall be applied to opposite sides of the cubes as cast, that is, not to the top and bottom. The axis of the specimen shall be carefully aligned with the centre of thrust of the spherically seated platen. No packing shall be used between the faces of the test specimen and the steel platen of the testing machine. As the spherically seated block is brought to bear on the specimen, the movable portion shall be rotated gently by hand so that uniform seating may be obtained.

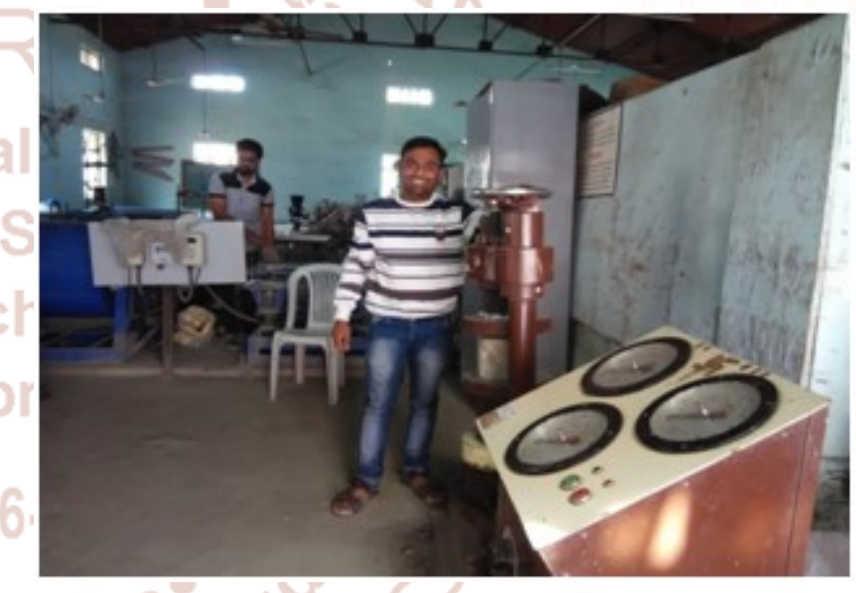

Figure-6 CTM machine in TOM lab. In J.T.M.C.O.E. Faizpur

\section{RESULT AND DISCUSSION}

\subsection{Compressive testing}

Testing of the cubes (M20) is carried out as per the IS 516:1959. The results of the test are as follows: 
International Journal of Trend in Scientific Research and Development (IJTSRD) ISSN: 2456-6470

Table-3 Results for Compressive Strength

\begin{tabular}{|c|c|c|c|c|c|c|c|c|c|c|}
\hline \multicolumn{11}{|c|}{ Result for compressive testing of fibres composite concrete cubes } \\
\hline \multicolumn{11}{|c|}{ Grade of concrete used : M20 } \\
\hline & $\begin{array}{c}\text { Cube } \\
\text { wt }\end{array}$ & $\begin{array}{c}\mathrm{W} / \\
\mathrm{c}\end{array}$ & $\begin{array}{c}\text { Fibre } \\
\text { fracti } \\
\text { on } \\
\end{array}$ & $\begin{array}{c}\text { Fibre } \\
\text { weight }\end{array}$ & Mixing & $\begin{array}{c}\text { Plastici } \\
\text { zer }\end{array}$ & $\begin{array}{c}7 \text { days } \\
\text { strengt } \\
\text { h }\end{array}$ & $\begin{array}{c}28 \text { days } \\
\text { strength } \\
\left(F_{\text {act }}\right) \\
\end{array}$ & $\mathbf{F}_{\mathrm{act}} / \mathbf{F}_{\mathrm{ck}}$ & Remark \\
\hline Unit & Kg & & $\%$ & Grams & $\mathbf{D} / \mathbf{W}$ & $\mathbf{Y} / \mathbf{N}$ & $\mathbf{N} / \mathbf{m m}^{2}$ & $\mathbf{N} / \mathbf{m m}^{2}$ & & \\
\hline $\begin{array}{c}\text { S. } \\
\text { No. }\end{array}$ & \multicolumn{10}{|c|}{ We have assumed that nominal mix of M20 gives minimum characteristic strength of $20 \mathrm{~N} / \mathrm{mm}^{2}$} \\
\hline 1 & 8.1 & $\begin{array}{l}0.5 \\
5\end{array}$ & 0 & 0 & $\mathrm{~W}$ & Y & 13.40 & 20 & 1 & Control \\
\hline 2 & 8.1 & $\begin{array}{l}0.5 \\
5\end{array}$ & 0.1 & 8.1 & $\mathrm{~W}$ & $\mathrm{Y}$ & 20.06 & 28.3 & 1.41 & Good \\
\hline 3 & 8.1 & $\begin{array}{l}0.5 \\
5\end{array}$ & 0.1 & 8.1 & & & 20.78 & 29.4 & 1.47 & Good \\
\hline 4 & 8.1 & $\begin{array}{l}0.5 \\
5\end{array}$ & 0.1 & 8.1 & $\bar{W}$ & & 24.49 & 28.9 & 1.45 & Good \\
\hline 5 & 8.1 & $\begin{array}{l}0.5 \\
5\end{array}$ & 0.2 & 16.2 & $\mathrm{~W} \odot$ & $\mathrm{Y}$ & 15.26 & 30.25 & 1.51 & Good \\
\hline 6 & 8.1 & $\begin{array}{l}0.5 \\
5\end{array}$ & 0.2 & 16.2 & $\mathrm{~W}$ & & 15.70 & 33.56 & 1.67 & Good \\
\hline 7 & 8.1 & $\begin{array}{l}0.5 \\
5\end{array}$ & 0.2 & 16.2 & W & Y & $\begin{array}{l}15.26 \\
\text { yrna }\end{array}$ & 32.05 & 1.60 & Good \\
\hline 8 & 8.1 & $\begin{array}{l}0.5 \\
5\end{array}$ & 0.3 & 24.3 & $\begin{array}{c}\mathrm{W} \\
\text { rend }\end{array}$ & $\ln S$ & 18.31 & 28.64 & 1.43 & Good \\
\hline 9 & 8.1 & $\begin{array}{l}0.5 \\
5\end{array}$ & 0.3 & 24.3 & $\mathrm{~W}$ & $\mathrm{Y}$ & 23.98 & 31.56 & 1.57 & Good \\
\hline 10 & 8.1 & $\begin{array}{l}0.5 \\
5\end{array}$ & 0.3 & 24.3 & D W $/ \mathrm{e}$ & $\mathrm{O} \mathrm{Yn}$ & 19.62 & 28.85 & 1.44 & Good \\
\hline
\end{tabular}

\section{Results and inference:}

From the above mention test, it is inferred from that up to $0.2 \%$ of fibre composite concrete; there is no need of the addition of the plasticizer. For $0.3 \%$ and $1 \%$ of fibre composite concrete plasticizer is required as per the specification. In case of the $1 \%$ fibre composite concrete the compressive strength of the specimen is compromised else it was efficient. So it can be inferred that as the percentage of the fibre is increased the compressive strength is compromised.

\section{Conclusion:}

The compressive strength is not compromised because of the addition of the fibres up to certain limit.

\subsection{Flexural test}

Testing of the cubes (M20) is carried out as per the IS 516. The results of the test are as follows: 
International Journal of Trend in Scientific Research and Development (IJTSRD) ISSN: 2456-6470

Table-4 Results for Flexural Test

\begin{tabular}{|c|c|c|c|c|c|c|c|c|}
\hline Sr no & W/c & $\begin{array}{c}\text { Fibre } \\
\text { fraction }\end{array}$ & $\begin{array}{c}\text { Fibre } \\
\text { weight }\end{array}$ & Mixing & Plasticizer & $\begin{array}{c}\text { Dead } \\
\text { weight }\end{array}$ & $\begin{array}{c}\text { Breaking } \\
\text { load }\end{array}$ & $\begin{array}{c}\text { Total load } \\
\text { taken }\end{array}$ \\
\hline Unit & & $\%$ & Grams & D/W & Y/N & Kg & Kg & Kg \\
\hline $\mathbf{1}$ & 0.5 & 0.1 & 37.80 & W & Y & 37.80 & 1256.00 & 1206.00 \\
\hline $\mathbf{2}$ & 0.5 & 0.1 & 37.80 & W & Y & 37.80 & 1036.00 & 986.00 \\
\hline $\mathbf{3}$ & 0.5 & 0.2 & 75.60 & W & Y & 37.80 & 1110.00 & 1060.00 \\
\hline $\mathbf{4}$ & 0.5 & 0.2 & 75.60 & W & Y & 37.80 & 1490.00 & 1440.00 \\
\hline $\mathbf{5}$ & 0.5 & 0.3 & 113.40 & $\mathrm{~W}$ & $\mathrm{Y}$ & 37.80 & 647.00 & 597.00 \\
\hline $\mathbf{6}$ & 0.5 & 0.3 & 113.40 & $\mathrm{~W}$ & $\mathrm{Y}$ & 37.80 & 750.00 & 700.00 \\
\hline
\end{tabular}

\subsection{Flexural test on tiles}

Specimen used was conforming to IS 1237:1980 and IS 456:2000. Size was as per the standards is $300 \mathrm{mmX} 300 \mathrm{mX} 25 \mathrm{~mm}$.

Table-5 Results for Fibre Composite Concrete Tiles

\begin{tabular}{|c|c|c|c|c|c|c|c|c|c|}
\hline & $\mathrm{W} / \mathrm{C}$ & $\begin{array}{c}\text { Fibre } \\
\text { fraction }\end{array}$ & $\begin{array}{c}\text { Fibre } \\
\text { weight }\end{array}$ & Mixing & Plasticizer & $\begin{array}{c}\text { Breaking } \\
\text { load }\end{array}$ & $\begin{array}{l}\text { Total load } \\
\text { taken }\end{array}$ & $\begin{array}{l}\text { Total load } \\
\text { taken }\end{array}$ & $\begin{array}{c}\text { Modulus } \\
\text { of } \\
\text { Rupture }\end{array}$ \\
\hline Unit & & $\%$ & Grams & $\mathrm{D} / \mathrm{W}$ & $\mathrm{Y} / \mathrm{N}$ & $\mathrm{Kg}$ & $\mathrm{Kg}$ & $\mathrm{N}$ & $\mathrm{N} / \mathrm{mm}^{2}$ \\
\hline $\begin{array}{l}\text { Sr } \\
\text { no }\end{array}$ & & & $\begin{array}{l}0 \\
+\infty\end{array}$ & , & onal & Journa & 9 & & \\
\hline 1 & 0.55 & 0 & 0 & W & TIOY Y & 185.00 & 155 & 1520.00 & 3.648 \\
\hline 2 & 0.55 & 0.3 & 16.2 & $\mathrm{~W}$ & aserch & 230.00 & 200 & 1962.00 & 4.708 \\
\hline 3 & 0.55 & 0.4 & 21.6 & $\mathrm{~W}$ & $\mathrm{Y}$ & 242.00 & 212 & 2079.72 & 4.991 \\
\hline 4 & 0.55 & 0.5 & 27 & $\mathrm{~W}$ & $\mathrm{Y}$ & 168.00 & 138 & 1353.78 & 3.249 \\
\hline
\end{tabular}

\section{Results and inference:}

It is possible to achieve good finish and satisfactory strength using banana fibre in concrete tiles. It also reduces the shrinkage cracks and also helps to increase the abrasion value of the tiles.

\section{Conclusion:}

Thus, it can be concluded that the major percentage of the fibre (about $0.4 \%$ ) can be used as an additive in concrete tiles without compromising on the strength and finish of the product.

\section{DISCUSSION WITH RESULT}

\subsection{Compressive testing}

From the above calculation, it's said that the compressive strength of concrete is higher at $0.2 \%$ of fibre and it should be decrease with increasing the percentage of fibre. The compressive strength of the concrete not significantly compromised due to addition of the fibres.

The percentage increase is inversely proportional to the compressive strength.

\section{Compressive Strength}

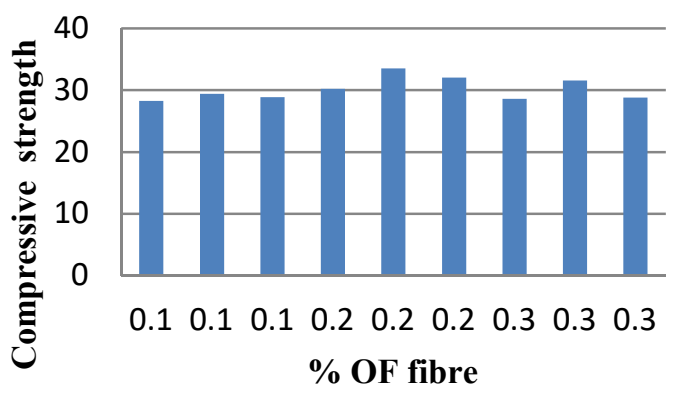

Graph-1 Compressive Strength Variation with Fibre Percentage 


\subsection{Flexural test}

From the above flexural test result it can be said that the percentage of fibre is increase than $2 \%$ then, decrease the bending moment. At the $0.2 \%$ of fibre the flexural strength of the concrete is also increase as compared to other percentage. Thus, it is advisable to avoid the use of fibres in high percentages. (Not more than $0.2 \%$ in concrete).

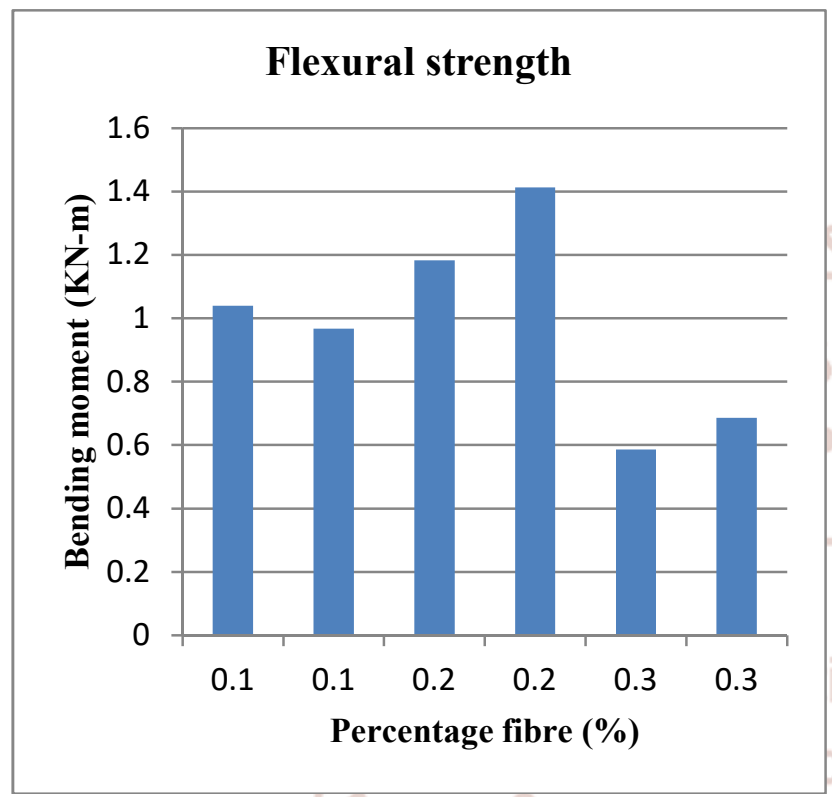

Graph-2 Graph of Percentage Fibre Vs Bending moment

\subsection{Transverse test for fibre composite concrete tiles}

Possible to achieve good finishing and satisfactory strength using the fibres and at the same time add reduced shrinkage cracks, increased abrasion value due to the fibres holding the slurry and reduced crack propagation. Major percentage of the fibres (about $0.4 \%$ ) can be used to suffice as an additive to concrete pavers.

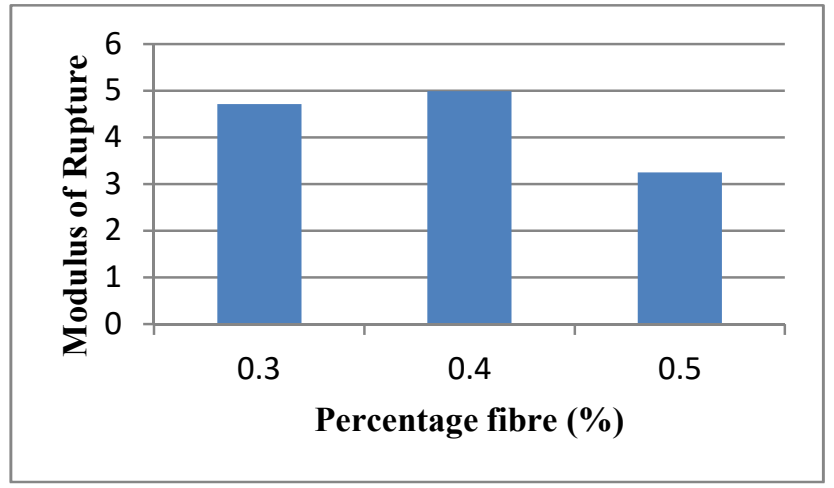

Graph-3 Graph of Percentage Fibre Vs Modulus of Rupture

\section{CONCLUSION AND RECOMMEDATION FOR FUTURE WORK}

\subsection{CONCLUSION}

From the project, we conclude that the banana fibre is effective to improve the strength of concrete at certain percentage. And the percentage of banana fibre is increase with increase the honey combing. The objective of the project is optimum utilization of the banana stem fibres as a composite in building materials. Analytical conclusions pertaining to the testing carried out under the scope of the project give us major understanding of how the concrete behaves due to addition of fibres.

From the above project report we are conclude as below:

1. In the compressive test, for $0.2 \%$ of fibre the compressive strength should be achieved maximum. So it is beneficial to use this percentage of banana fibre in the concrete.

2. At the $0.2 \%$ of fibre the flexural strength of the concrete is also increase as compared to other percentage. Thus, it is advisable to avoid the use of fibres in high percentages. (Not more than $0.2 \%$ in concrete).

3. The major percentage of the fibre (about 0.4 $\%$ ) can be used as an additive in concrete tiles without compromising on the strength and finish of the product. Possible to achieve good finishing and satisfactory strength using the fibres and at the same time add reduced shrinkage cracks, increased abrasion value due to the fibres holding the slurry and reduced crack propagation .

4. For the plastering result we conclude that, 0.5 $\%$ of fibre is useful to reduced shrinkage cracks. And more than $0.5 \%$ fibre are affected on plastering.

5. The strength of concrete is not compromised because of the addition of the fibres up to certain limit.

6. It thus would be a major subject to study to understand the behaviour of the fibre in a mix design and then prescribe standards for the use of the fibres.

\subsection{Recommendation for future work}

These are some recommendation for future work in this field. 
1. Comparative cost analysis could be done on banana fibre mix concrete and conventional concrete.

2. The effect of banana fibre on the various properties of concrete could also be analyzed.

3. A further study should be launched to optimize the use of banana fibre in building structures.

4. It is suggested that a pilot project should be constructed from the banana fibre mix concrete and mortar to determine how it improve various properties of conventional concrete.

5. The long term properties of banana fibre mix concrete and mortar should also be determined by detailed study.

\section{REFERENCES}

1) Indian standard for properties of natural source aggregates IS 383-1997.

2) IS 516-1959 for testing of concrete.

3) IS 456-2000 for nominal design of concrete.

4) Krishna R. and Sandararajan (2005)Study On Addition Of The Natural Fibers Into Concrete, International Journal Of Scientific \& Technology Research Volume 2, Issue 11, November 2013.

5) Kulkarni A.G., Satyanarayana K.G., Rohtagi P.K, Vijayam K, J. (1983) Mater. Sci., 18, 2290-2296

6) Mohanty A.K., Mishra M, Drzal L.T., (2001), Composite Interfaces, Vol. 8, No. 5, pp. 313-343

7) Maries I, Neelakantan N. R., Oommen Z, Joseph K,Thomas S, Journal of Applied Polymer Science, Volume 96, Issue 5 (p 1699-1709)
8) Mukhopadhyay S., Vijay G., Talwade R., Dhake J.D., Pegoretti A, August 2006 , Some Studies on Banana Fibres, International conference on Advances in Fibrous Materials, Nonwoven and Technical Textiles, 7-9, Coimbatore, India.

9) Pothan, L. A.; Thomas, S.; Neelakantan, N. R. J (1997) ReinfPlast Compos 16, 744.

10) Rao, M M., Mohana R. K., (2007), Extraction and tensile properties of natural fibres: Vakka, date and bamboo, Composite Structures 77, 288-295.

11) Samarth Mukhopadhyay, Ph.D. Raul Fangueiro, Ph.D. University of Minho, PORTUGAL- Banana Fibres - Variability and Fracture Behaviour.

12) Harajli \& Salloukh(1997). In addition to industrial fibers, natural organic and mineral fibers have been also investigated in reinforced concrete. Wood, banana, sisal, jute, bamboo, coconut, asbestos and rock wool.

13) Elie Awwad, MounirMabsout, Bilal Hamad and Helmi Khatib, Preliminary Studies On The Use Of Natural Fibers In Sustainable Concrete, Lebanese Science Journal, Vol. 12, No. 1, 2011.

14) Majjidali, Natural fibres as construction materials*, Journal of Civil Engineering and Construction Technology Vol. 3(3), pp. 80-89, March 2012 